\title{
AVALIAÇÃO FÍSICO-QUÍMICA E SENSORIAL DE BISCOITO TIPO COOKIES ENRIQUECIDOS COM FARINHA DO CAROÇO E POLPA DO AÇAÍ
}

Physical-chemical and sensory evaluation of cookies type cookies enriched with sugar flour and pasta of physical and chemical cookies

Evaluación físico-química y sensorial de cookies tipo cookies enriquecidas com harina de azúcar y pastas de cookies físicas y químicas

Samara Kelly Amaral Barros ${ }^{* 1}$, Andressa Sousa Pereira ${ }^{1}$, Silvia Myrelly Tavares da Silva ${ }^{1}$, Douglas Martins da Costa ${ }^{2}$, Caroline Roberta Freitas Pires ${ }^{3}$, Adriana Régia Marque de Souza $^{3}$

${ }^{1}$ Discente do Programa de Pós-graduação em Ciência e Tecnologia de Alimentos, Universidade Federal do Tocantins, Palmas, Brasil.

${ }^{2}$ Biólogo do Laboratório de Análises de Alimentos - LANA, Universidade Federal do Tocantins, Palmas, Brasil.

${ }^{3}$ Docente do Programa de Pós-graduação em Ciência e Tecnologia de Alimentos, Universidade Federal do Tocantins, Palmas, Brasil.

*Correspondência: Laboratório de Tecnologia de Alimentos, Complexo Laboratorial de Nutrição, Universidade Federal do Tocantins, Av. NS 15, 109 Norte, Palmas, Tocantins, Brasil. CEP:77.010-090. e-mail: aramasly@gmail.com

\section{Artigo recebido em 06/03/2020 aprovado em 27/03/2020 publicado em 31/03/2020}

\section{RESUMO}

A procura dos consumidores por produtos que apresentem elevado valor nutricional e/ou benefícios à saúde é crescente, logo, este trabalho tem o objetivo de elaborar biscoitos tipo cookies utilizando diferentes concentrações da farinha do caroço do açaí e avaliar suas características físico-químicas e aceitação sensorial. Foram elaboradas três formulações: $20 \mathrm{~g}$ (T1), $50 \mathrm{~g}$ (T2) e $70 \mathrm{~g}$ (T3) de farinha do caroço de açaí. Os cookies foram analisados quanto à umidade, cinzas, pH, Brix, acidez, ratio e cor. Os testes sensoriais foram realizados com 65 julgadores não treinados, utilizando uma escala hedônica de nove pontos para avaliação dos atributos, bem como o teste de intenção de compra e preferência. O conteúdo de cinzas e umidade dos cookies estão de acordo com a legislação brasileira de alimentos. $\mathrm{O}$ pH e acidez variou segundo a quantidade de farinha adicionada. A formulação T1 adquiriu menor luminosidade $\left(\mathrm{L}^{*}\right)$ e intensidade de vermelho $\left(+\mathrm{a}^{*}\right)$ maior, em comparação as demais. A análise sensorial demonstrou satisfatória aceitação dos cookies. Quanto à intenção de compra, as formulações T1 e T2 foram bem aceitas, demostrando que seria viável uma possível comercialização. Este produto pode ser considerado uma fonte de fibras, pois contém de 20 a 70g/100g de fibra para alimentos sólidos.

Palavras-chave: Euterpe oleracea; Desenvolvimento de novos produtos; Análise sensorial.

\section{ABSTRACT}

Demand for consumer products that have high nutritional value and / or health benefits is growing, logo, this work aims to elaborate types of cookies, using different types of use of acai stone meal and evaluation of physical characteristics. and sensory chemistry. Three formulations were elaborated: $20 \mathrm{~g}$ (T1), $50 \mathrm{~g}$ (T2) and $70 \mathrm{~g}$ (T3) of açai stone flour. Cookies were analyzed for moisture, ash, $\mathrm{pH}$, Brix, acidity, ratio and color. Sensory tests were performed with 65 untrained judges, using a nine-point hedonic scale for attribute evaluation, as well as the purchase intention and preference test. The ash content and the amount of cookies are in accordance with Brazilian food law. The $p H$ and acidity varied according to the amount of flour added. Inclusion T1 bought lower brightness $(L *)$ and higher 
intensity of red $(+a *)$, compared to others. Sensory analysis showed satisfactory acceptance of cookies. As for purchase intention, as the $T 1$ and $T 2$ formulations were well accepted, demonstrating that a possible commercialization would be viable. This product can be considered a fiber source as it contains 20 to $70 \mathrm{~g} / 100 \mathrm{~g}$ of heavy food fiber.

Keywords: Euterpe oleracea; Development of new products; Sensory analysis.

\section{RESUMEN}

La demanda de productos de consumo que tienen un alto valor nutricional y / o beneficios para la salud está creciendo, este trabajo tiene como objetivo elaborar tipos de galletas, utilizando diferentes tipos de uso de harina de piedra de acai y evaluación de características físicas. y química sensorial. Se elaboraron tres formulaciones: 20 $g(T 1), 50 g(T 2)$ y $70 g$ (T3) de harina de piedra de açaí. Las cookies fueron analizadas para humedad, cenizas, $p H$, Brix, acidez, proporción y color. Las pruebas sensoriales se realizaron con 65 jueces no capacitados, usando una escala hedónica de nueve puntos para la evaluación de atributos, así como la prueba de intención de compra y preferencia. El contenido de cenizas y la cantidad de cookies están de acuerdo con la legislación alimentaria brasileña. El pH y la acidez variaron según la cantidad de harina añadida. La inclusión T1 compró un brillo más bajo $\left(L^{*}\right)$ y una mayor intensidad de rojo $(+a *)$, en comparación con otros. El análisis sensorial mostró una aceptación satisfactoria de las cookies. En cuanto a la intención de compra, ya que las formulaciones T1 y T2 fueron bien aceptadas, lo que demuestra que una posible comercialización sería viable. Este producto puede considerarse una fuente de fibra ya que contiene de 20 a $70 \mathrm{~g} / 100 \mathrm{~g}$ de fibra de alimentos pesados.

Descriptores: Euterpe oleracea; Desarrollo de nuevos productos; Análisis sensorial.

\section{INTRODUÇÃO}

O Brasil ocupa a posição de $4^{\circ}$ maior produtor mundial de biscoitos, com o registro de 1.366 milhões de toneladas produzidas em 2018, o que representou $2,8 \%$ de crescimento sobre 2008 em que foram produzidas 1,18 milhões de toneladas (ABIMAPI, 2018).

Os produtos de confeitaria são usados como veículos para incorporação de nutrientes e compostos bioativos (Mareti et al., 2010). Entre estes, os biscoitos tipo cookies se destacam pelas facilidades tecnológicas que propiciam ao comportarem grande variedade de ingredientes e formulações, assim como também grande flexibilidade nas características do produto (Carneiro et al., 2012). Além de apresentarem grande consumo, longo tempo de comercialização e boa aceitação, sobretudo entre as crianças (Fasolin et al., 2007).

A demanda por alimentos fontes de ingredientes funcionais é crescente por parte da população, o que serviu de incentivo para o desenvolvimento e a industrialização de biscoitos fortificados de fibras ou proteínas, por meio da adição de cereais, frutas e vegetais (Gomaa e Boye, 2013; Alvarez e Barbut, 2013).

$\mathrm{O}$ aproveitamento integral e/ou parcial de resíduos não utilizados de frutas e hortaliças pode ser aproveitada na elaboração de novos produtos alimentícios, visando a redução de custos das preparações e de desperdício de alimentos, contribuindo para o combate à desnutrição e à fome (Silva et al., 2019).

$\mathrm{O}$ alto teor de fibras contido nos resíduos da indústria de alimentos pode ser usado na preparação de biscoitos, aumentando a oferta de produtos com maior teor de fibras, tanto para consumidores saudáveis quanto para aqueles que sofrem de constipação intestinal, altos níveis de colesterol e obesidade (Mauro et al. 2010; Han et al. 2010; Baiano et al. 2011).

Dentre as frutas que apresentam perdas durante o processamento está o açaí. O açaiziero (Euterpe oleracea Mart.) pertence à ordem Arecales, à família Palmae e ao gênero Euterpe. $O$ fruto caracteriza-se como uma drupa globosa com diâmetro entre 1 e $2 \mathrm{~cm}$ 
e pesando em média 1,5 gramas, o epicarpo na maturação é roxo ou verde principalmente devido às suas antocianinas e fenólicos (Souza et al., 2011; Bonomo et al., 2014). O endocarpo é volumoso e duro, correspondendo a $85 \%$ do peso total do fruto, e apresenta um alto valor em fibras despertando o interesse comercial como potencial alimento funcional.

A demanda da indústria alimentícia pelo desenvolvimento de novos produtos, com ênfase no mercado de biscoitos, no interesse de reduzir os impactos ambientais e a procura dos consumidores por produtos que apresentem elevado valor nutricional e/ou benefícios à saúde, teve-se como objetivo elaborar formulações de biscoitos tipo cookies utilizando diferentes concentrações da farinha do caroço do açaí e avaliar suas características físico-químicas e aceitação sensorial.

\section{MATERIAIS E MÉTODOS}

\section{Matéria prima}

Os frutos de açaí foram adquiridos na zona rural do município de Palmas - TO, no estádio de maturação comercial. Os frutos foram transportados para o Laboratório de Tecnologia de Alimentos da Universidade Federal do Tocantins (UFT), onde foram previamente lavados e sanitizados com solução de hipoclorito de sódio a 100ppm, por 10 minutos e em seguida congelado $-18^{\circ} \mathrm{C}$ até o uso. Para obtenção da polpa e farinha do caroço foi realizado o despolpamento manualmente. Os demais ingredientes para a formulação dos biscoitos tipo cookies foram obtidos no comércio local.

\section{Processamento da farinha do caroço do açaí}

Os caroços foram doados por uma empresa localizada no estado do Goiás e encaminhados para a o Laboratório de Tecnologia de Alimentos da
Universidade Federal do Tocantins, campus Palmas. Cerca de $500 \mathrm{~g}$ foram secos em estufa com circulação de ar a $50^{\circ} \mathrm{C}(28 \mathrm{~h})$ até atingir um teor final de água de cerca de 5\%. Após a secagem, o caroço de açaí foi moído em porções de $50 \mathrm{~g}$ usando um moinho de facas (tipo Willye modelo STAR FT- 50) por cerca de $20 \mathrm{~s}$. Posteriormente, o resíduo triturado foi peneirado e seu produto gerado foi moído em moinho de martelo (Vieira MCS $280(05 \mathrm{cv}))$ em peneira de furo maior de $0.7 \mathrm{~mm}$ e em seguida em peneira de furo menor de 0.3 mm. O produto gerado dos grãos de açaí retidos das peneiras foi classificado como farinha. A mesma apresentou aparência semelhante a farinha de trigo.

\section{Elaboração e preparo dos biscoitos tipo cookies}

Os biscoitos tipo cookies foram elaborados no Laboratório de Tecnologia de Alimentos da Universidade Federal do Tocantins. Para o desenvolvimento das formulações de biscoitos foram realizados três tratamentos. O tratamento 1 (T1) corresponde a formulação com adição de $20 \%$ de farinha do caroço do açaí. O tratamento 2 (T2) corresponde a formulação com adição de $50 \%$ de farinha do caroço do açaí. O tratamento 3 (T3) com adição de $70 \%$ de farinha do caroço do açaí.

Para preparação das formulações todos os ingredientes foram pesados em balança digital eletrônica. A massa dos cookies foi processada manualmente da seguinte forma: Os ingredientes secos foram misturados até obtenção de uma massa contínua. Em seguida, formou-se um creme homogêneo com adição da margarina vegetal, açúcar e ovos. Esse método foi utilizado para obtenção de melhor homogeneidade da massa. O tempo de mistura total foi de aproximadamente 10 minutos para todas as formulações. A massa foi moldada com o auxílio de uma forma circular, os biscoitos foram assados a $180^{\circ} \mathrm{C}$ 
$\pm 5^{\circ} \mathrm{C}$ por 20 minutos. Os biscoitos foram resfriados à temperatura ambiente e acondicionados em sacos de polipropileno e armazenados.

As concentrações dos ingredientes utilizados em cada tratamento estão relacionadas na Tabela 1.

Tabela 1. Ingredientes utilizados no preparo de biscoitos tipo cookies acrescido da farinha do caroço do açaí.

\begin{tabular}{lccc}
\hline \multirow{2}{*}{ Ingredientes } & \multicolumn{3}{c}{ Formulações } \\
\cline { 2 - 4 } & $\mathrm{F} 1$ & $\mathrm{~F} 2$ & $\mathrm{~F} 3$ \\
\hline Farinha o caroço do açaí $(\mathrm{g})$ & 20 & 50 & 70 \\
Polpa de açaí $(\mathrm{g})$ & 70 & 70 & 70 \\
Proteína de soja (g) & 50 & 50 & 50 \\
Aveia em flocos (g) & 80 & 80 & 80 \\
Margarina sem sal (g) & 120 & 120 & 120 \\
Ovo (g) & 50 & 50 & 50 \\
Uva passas (g) & 30 & 30 & 30 \\
Sucralose (g) & 4 & 4 & 4 \\
\hline * Sem adição de água & & &
\end{tabular}

\section{Determinações físico-químicas}

A composição centesimal da farinha do caroço do açaí foi determinada por meio das análises de umidade, conforme técnica descrita pela metodologia 925.09 da AOAC (AOAC, 1995); extrato etéreo, conforme técnica 920.85 da AOAC, e posteriormente determinados por gravimetria (AOAC, 1995); nitrogênio total, segundo o método de Kjeldahl e conversão em proteína bruta utilizando-se o fator 6,25, segundo metodologia 920.87 da AOAC (AOAC, 1995); fibra bruta conforme a metodologia 991.43 (AOAC, 1995); resíduo mineral fixo, por incineração em mufla a $550^{\circ} \mathrm{C}$, segundo o método 923.03 descrito pela AOAC (AOAC, 1995). Carboidratos foram obtidos pelo somatório dos valores das determinações de umidade, cinzas, proteína e lipídeos subtraído de cem.

$\mathrm{O} \mathrm{pH}$ das três formulações dos biscoitos tipo cookies foi determinado utilizando um potenciômetro digital segundo a técnica da AOAC (1995). A acidez titulável total foi determinada por titulação com $\mathrm{NaOH}$ 0,01N de acordo com a técnica AOAC (1995) e expressa em \% de ácido cítrico/100g de polpa. Os sólidos solúveis totais foram determinados utilizandose um refratômetro com compensação de temperatura automática a $25^{\circ} \mathrm{C}$ e expressos em \%, segundo a AOAC (1995). Os resultados foram expressos em ${ }^{\circ}$ Brix. O "ratio" foi calculado dividindo se o valor de sólidos solúveis ( ${ }^{\circ}$ Brix) pelo valor da acidez total titulável.

A umidade dos biscoitos foi determinada por secagem direta em balança infravermelha utilizando $3 \mathrm{~g}$ de cada amostra pesada. As cinzas foram determinadas pelo método de gravimetria, mediante incineração da amostra em mufla a $550^{\circ} \mathrm{C}$ até obtenção de cinzas clara (AOAC, 1995).

Para leitura da coloração dos cookies foi utilizado equipamento colorímetro digital. As regiões analisadas de cada cookie foram superioras e inferiores. Os resultados foram expressos em valores $\mathrm{L}^{*}, \mathrm{a}^{*} \mathrm{e} \mathrm{b}^{*}$, onde os valores de $\mathrm{L}^{*}$ expressam em porcentagem de luminosidade $(0 \%=$ negro e $100 \%=$ branco $), a^{*}$ representa as cores vermelha (+) ou verde (-) e b* cor amarela (+) ou azul (-). As determinações foram efetuadas com um mínimo de três repetições.

\section{Informação Nutricional}

Para proceder aos cálculos necessários para obter as informações nutricionais, utilizou-se o manual sobre Rotulagem Nutricional Obrigatória da Anvisa (2005). A composição centesimal da farinha do caroço do açaí está descrita na Tabela 2; a composição da proteína de soja, aveia em flocos, margarina, uva passas e sucralose pela informação nutricional contida no rótulo dos produtos; os ovos e a polpa de açaí de acordo com a Tabela Brasileira de Composição de Alimentos da Universidade Estadual de Campinas (2011).

O valor calórico das amostras foi calculado utilizando os fatores de conversão 4,0 para carboidrato e proteína e 9,0 para lipídios. 
Tabela 2. Composição centesimal da farinha do caroço do açaí. Valores expressos em $100 \mathrm{~g}$ de matéria integral.

\begin{tabular}{lc}
\hline Componentes & Médias \\
\hline Umidade $(\mathrm{g})$ & 9,06 \\
Lipídeos $(\mathrm{g})$ & 1,7 \\
Proteína $(\mathrm{g})$ & 6,7 \\
Carboidrato $(\mathrm{g})$ & 81,24 \\
Fibras $(\mathrm{g})$ & 47,62 \\
Cinzas $(\mathrm{g})$ & 1,3 \\
Valor energético (kcal) & 367,06 \\
\hline
\end{tabular}

\section{Análise Sensorial}

Para a avaliação da aceitação dos biscoitos tipo cookies, utilizou-se amostras das três formulações (T1, T2 e T3) descritas anteriormente. Os testes de aceitação foram realizados na Universidade Federal do Tocantins, com 65 julgadores não treinados, homens e mulheres com idade entre 18 e 60 anos, consumidores de cookies. As amostras codificadas com algarismos de três dígitos contendo 20 gramas de biscoito foram servidas para cada julgador, em cabines individuais iluminadas com luz fluorescente e acompanhadas de um copo de água mineral para a lavagem do palato.

No teste de aceitabilidade foram avaliados os atributos de cor, aroma, sabor, textura e impressão global, utilizando-se escala hedônica estruturada de nove pontos (1=desgostei muitíssimo; 5=nem gostei/nem desgostei; 9=gostei muitíssimo). Os provadores foram instruídos a julgar inicialmente a cor dos biscoitos pela observação visual e depois aroma, sabor e textura.

A intenção de compra do produto foi avaliada através de uma escala de cinco pontos, onde $1=$ certamente não compraria e $5=$ certamente compraria. Para os testes sensoriais foi mantido o máximo de individualidade necessária para a avaliação das amostras pelos provadores. A equipe de aplicação foi responsável pelo controle, transmissão de instrução e orientação geral dos testes.
Para avaliar a preferência dos provadores utilizou-se um teste de ordenação, onde os provadores foram orientados a ordenar em ordem crescente as amostras de acordo com a sua preferência.

\section{Delineamento Experimental}

Os resultados foram submetidos à Análise de Variância (ANOVA) e ao teste de comparação de médias de Tukey, com a utilização do programa SISVAR (Ferreira, 2011). Os dados da análise sensorial foram apresentados em tabelas e os atributos (cor, aroma, sabor, textura e impressão global) na forma de histogramas relacionando o percentual de indivíduos e as notas atribuídas. Os resultados obtidos pelo teste de ordenação foram tratados estatisticamente pelo método de Friedman.

\section{RESULTADOS E DISCUSSÃO}

Os resultados da avaliação físico-química dos biscoitos das formulações testadas (acrescidos com $20 \%, 50 \%$ e $70 \%$ g de farinha de açaí) estão apresentados na Tabela 3 .

Tabela 3. Composição físico-química dos biscoitos tipo cookies enriquecidas com farinha do caroço do açaí. Valores expressos em $100 \mathrm{~g}$ de matéria integral.

\begin{tabular}{lccc}
\hline \multirow{2}{*}{ Componentes } & \multicolumn{3}{c}{ Formulações } \\
\cline { 2 - 4 } & $\mathrm{T} 1$ & $\mathrm{~T} 2$ & $\mathrm{~T} 3$ \\
\hline Umidade $(\mathrm{g})$ & 3,41 & 3,82 & 4,64 \\
Cinzas $(\mathrm{g})$ & 2,17 & 2,0 & 3,85 \\
pH & 6,04 & 5,98 & 6,02 \\
SST $\left({ }^{\circ}\right.$ Brix.) & 7 & 8 & 7 \\
ATT $(\%)$ & 0,06 & 0,05 & 0,04 \\
Ratio & 109,48 & 154,91 & 158,14 \\
Cor $\left(\mathrm{L}^{*}\right)$ & 24,35 & 25,36 & 24,51 \\
Cor $\left(\mathrm{a}^{*}\right)$ & 4,07 & 4,78 & 4,35 \\
Cor $\left(\mathrm{b}^{*}\right)$ & 8,7 & 8,91 & 8,41 \\
\hline
\end{tabular}

Quando analisados os resultados percebe-se que as amostras para os teores de cinza, apresentaram valores compreendidos entre 2 e 3,85\%. Azevedo et al. (2015) determinaram de 1,44 a 1,50\% de cinzas para os 
biscoitos elaborados com pó de açaí orgânico. Os teores de cinzas encontrados para os cookies em estudo estão de acordo com a legislação brasileira de alimentos e bebidas, cujo teor máximo de cinzas permitido em biscoitos é de 4,0\% (Brasil, 2005).

Em relação aos teores de umidade todas as formulações ficaram dentro do padrão estipulado pela Comissão Nacional de Normas e Padrões de Alimentos, o qual o teor de umidade deve ser no máximo 14,0\% (Brasil, 2005). Os valores observados nas três formulações foram abaixo aos obtidos por Lima et al. (2015) que estudaram cookies acrescidos de farinha da fibra do açaí e observaram valores de umidade de 6,26 a $8,45 \%$.

Carneiro et al. (2012) ao avaliarem a composição química de biscoitos tipo cookies acrescidos com pó de açaí orgânico, observaram teores de umidade de 6,74 a 7,10\%. Segundo Madrona e Almeida (2008) menores percentuais de umidade em produtos alimentícios são ideais para um aumento de seu tempo de comercialização, pois a baixa umidade é capaz de inibir o crescimento de microrganismos e provocar modificações na textura.

Houve uma variação significativa de $\mathrm{pH}$ e acidez de acordo com os dados obtidos, foi observado que a Formulação 1 com menor quantidade de farinha do caroço do açaí (20 g), obteve $\mathrm{pH}$ próximo a neutralidade $(6,04)$ e acidez menor que as outras formulações. A Formulação 3 com $50 \mathrm{~g}$ de farinha do caroço do açaí ficou fora do padrão estipulado Maciel et al. (2008) em que a faixa normal de pH para biscoitos é de entre 6,5 e 8,0 .

O açaí por ter uma cor marcante, a formulação F1 (20 g de farinha do caroço do açaí), adquiriu uma menor luminosidade ( $\left.\mathrm{L}^{*}\right)$ e uma intensidade de vermelho $\left(+a^{*}\right)$ maior (Tabela 3$)$, quando comparada a Formulação 3. A formulação $\mathrm{C}$ com maior concentração da farinha do caroço do açaí (70 g), obteve maior luminosidade e menor intensidade de vermelho na sua composição. Avaliando a intensidade de amarelo $\left(+b^{*}\right)$, a Formulação 2 apresentou maior intensidade.

No estudo de Azevedo et al. (2015) a amostra com menor concentração da farinha de açaí apresentou menor luminosidade e maior intensidade de vermelho. Já a amostra com maior concentração da farinha obteve maior luminosidade e menor intensidade de vermelho. Em relação a intensidade de amarelo, a formulação com maior concentração de farinha teve maio intensidade.

Para verificar a aceitação das amostras dos biscoitos tipo cookies pelos consumidores, realizou-se um teste sensorial de aceitação e intenção de compra. A análise sensorial foi realizada com três amostras com diferentes concentrações de farinha do caroço do açaí e os dados estão apresentados na Tabela 4.

Tabela 4. Valores médios das notas obtidas das amostras de biscoitos tipo cookies com farinha do caroço do açaí.

\begin{tabular}{ccccccc}
\hline Formulações & Cor & Aroma & Sabor & Textura & Avaliação Global & Intenção de Compra \\
\hline T1 & $6,92 \pm 0,21^{\mathrm{a}}$ & $6,73 \pm 0,23^{\mathrm{a}}$ & $6,53 \pm 0,24^{\mathrm{a}}$ & $6,2 \pm 0,24^{\mathrm{a}}$ & $6,56 \pm 0,22^{\mathrm{a}}$ & $3,35 \pm 0,13^{\mathrm{a}}$ \\
T2 & $6,53 \pm 0,21^{\mathrm{a}}$ & $6,15 \pm 0,23^{\mathrm{a}}$ & $5,35 \pm 0,24^{\mathrm{b}}$ & $6,07 \pm 0,24^{\mathrm{a}}$ & $5,83 \pm 0,22^{\mathrm{ab}}$ & $2,91 \pm 0,13^{\mathrm{a}}$ \\
T3 & $6,93 \pm 0,21^{\mathrm{a}}$ & $6,29 \pm 0,23^{\mathrm{a}}$ & $4,56 \pm 0,24^{\mathrm{b}}$ & $5,72 \pm 0,24^{\mathrm{a}}$ & $5,16 \pm 0,22^{\mathrm{b}}$ & $2,29 \pm 0,13^{\mathrm{b}}$ \\
\hline
\end{tabular}

*Letras iguais na mesma coluna não diferem significativamente entre si pelo Teste de Tukey $(\mathrm{p}<0,05)$.

De acordo com os resultados, observa-se que para o atributo cor, aroma e textura não houve diferença significativa entre as três formulações tendo seus valores situados na escala entre os termos "não gostei, nem desgostei" e "gostei ligeiramente". 
Para o atributo sabor a formulação 1 ( $20 \mathrm{~g}$ de farinha do caroço do açaí) se diferiu significativamente das demais formulações (T2 e T3) ao nível de 5\% de significância pelo teste de Tukey.

Quanto a avaliação global os biscoitos tipo cookies com $20 \%$ de farinha se diferiu significativamente da formulação com $70 \%$ de farinha do caroço do açaí, e não se diferiu da formulação com $50 \%$ de farinha ao nível de 5\% de significância pelo teste de Tukey. Em relação à intenção de compra não foi observada diferença estatística significativa entre as amostras T1 e T2, porém a amostra T3 se diferiu estatisticamente das demais formulações.

Apesar das elevadas notas em todos os parâmetros estudados, os provadores declararam ter dúvidas se comprariam as três formulações de cookies.

Para os atributos cor (Figura 1) e aroma (Figura 2) observa-se que mais de $60 \%$ dos provadores atribuíram notas entre 6 a 9 , valores estes correspondendo entre os termos "gostei ligeiramente" e "gostei muitíssimo".

Figura 1. Histogramas de frequência quanto à avaliação sensorial da cor dos biscoitos tipo cookies.

\section{Cor}

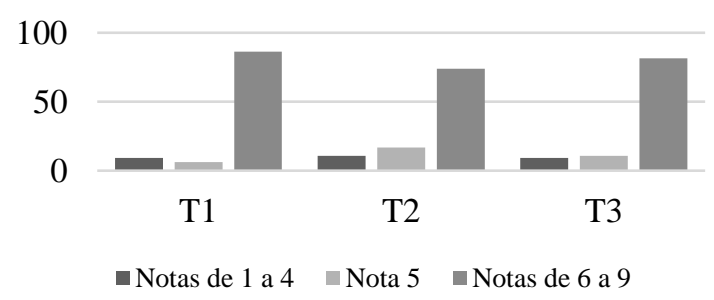

Figura 2. Histogramas de frequência quanto à avaliação sensorial do aroma dos biscoitos tipo cookies.

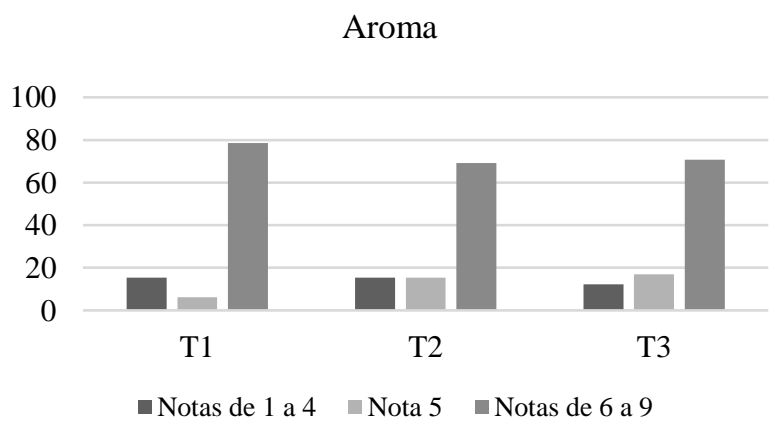

A cor do cookie com $50 \%$ de farinha do caroço de açaí a menos aceita (Figura 1), possivelmente, devido à forte tonalidade roxa proporcionada pela quantidade de farinha incorporada ao biscoito. Desse modo, percebe-se que a cor dos biscoitos está relacionada com os ingredientes contidos na formulação. Além desse fator, o escurecimento dos biscoitos pode ter sido afetado pela caramelização e pela Reação de Maillard, durante o assamento (Perez e Germani, 2007).

Observando o parâmetro sabor dos biscoitos tipo cookies (Figura 3) é possível afirmar que o tratamento $1 \mathrm{com} 20 \mathrm{~g}$ de farinha do caroço do açaí foi que obteve o maior percentual de notas maiores que 6 (> 60\%). A amostra com 70g de farinha do caroço do açaí, por sua vez, apresentou o maior percentual de notas de 1 a 4 (> 60\%), demonstrando que esta formulação foi menos aceita pelos julgadores.

Figura 3. Histogramas de frequência quanto à avaliação sensorial do sabor dos biscoitos tipo cookie.

Sabor

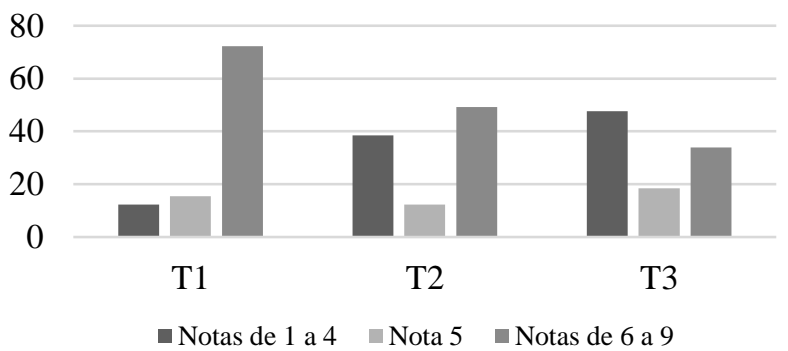

Acredita-se, que esse resultado seja devido à introdução de maior quantidade de farinha do caroço do açaí (composta basicamente de carboidratos complexos). Vale ressaltar que a quantidade de sucralose e uva passas permaneceu constante nas três formulações, porém percebe-se que esta quantidade não foi suficiente para o tratamento 3, visto que alguns provadores comentaram que amostra com $70 \%$ de farinha do caroço do açaí "Poderia ser mais doce".

Observando o parâmetro textura é possível afirmar que o cookie enriquecido com $20 \%$ de farinha 
do caroço do açaí foi tão bem aceito quanto a amostra contendo 50\% de farinha. As notas atribuídas pelos provadores situaram-se dentro da zona de aceitação (notas maiores que 6) (Figura 4).

Figura 4. Histogramas de frequência quanto à avaliação sensorial da textura dos biscoitos tipo cookies.

\section{Textura}

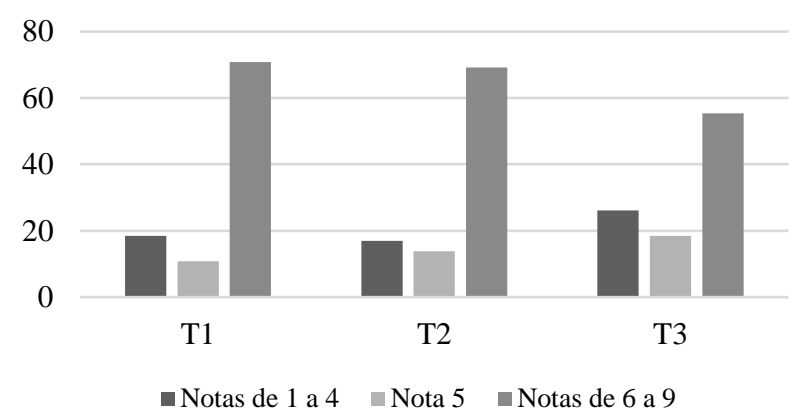

Com relação a avaliação global (Figura 5). Observa-se que mais de $50 \%$ dos provadores atribuíram notas entre 6 a 9, valores estes correspondendo entre os termos "gostei ligeiramente" e "gostei muitíssimo" (Figura 5).

Figura 5. Histogramas de frequência quanto à avaliação sensorial de impressão global dos biscoitos tipo cookies.

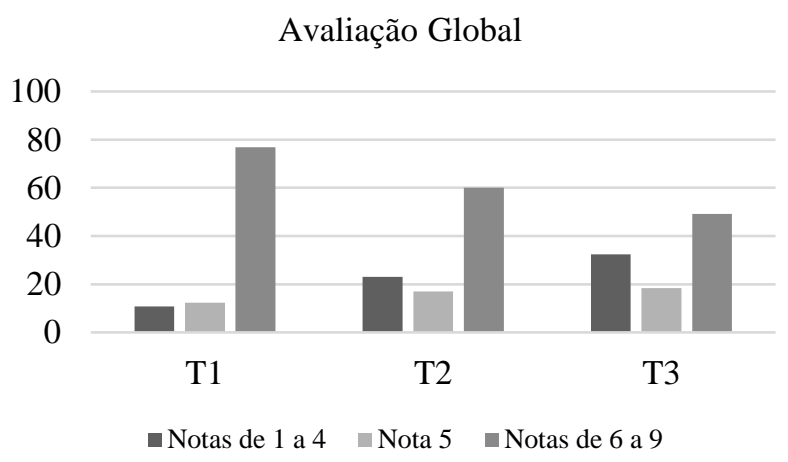

Seguido do teste de aceitação, foi utilizada uma escala de intenção de compra (Figura 6). Pode-se utilizá-la como indicativo de possível venda do produto.

Quando questionados sobre a intenção de compra, aproximadamente, $52 \%$ dos provadores atribuíram notas maiores que 4, valores estes correspondendo entre os termos "provavelmente e/ou certamente comprariam" biscoitos tipo cookies acrescido de $20 \%$ de farinha do caroço do açaí, $38 \%$ dos provadores afirmaram que "provavelmente e/ou certamente comprariam" cookies enriquecidos com $50 \%$ de farinha, enquanto $10 \%$ afirmaram que "provavelmente comprariam" biscoitos com $70 \%$ de farinha.

Figura 6. Histogramas de frequência quanto intenção de compra dos biscoitos tipo cookies.

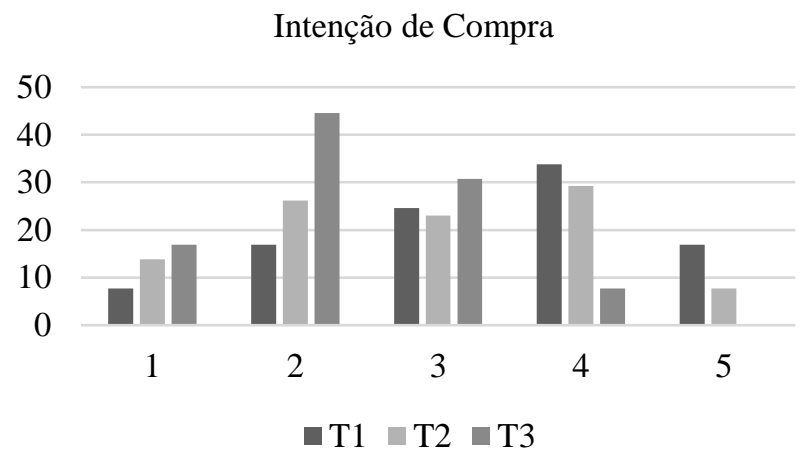

Legenda: (1). Certamente não compraria; (2). Provavelmente não compraria; (3). Não sei; (4). Provavelmente compraria; (5). Certamente compraria.

Apenas, aproximadamente, $62 \%$ dos provadores afirmaram que "certamente ou provavelmente não comprariam" cookies acrescidos com $70 \%$ de farinha do caroço do açaí. Este resultado mostra a baixa aceitação do tratamento 3 apresentada aos provadores.

Comparando-se os módulos da diferença com a diferença mínima significativa (DMS), conforme mostrado na Tabela 5 pode-se afirmar que houve diferença estatística significativa quanto à preferência entre as amostras de biscoitos tipo cookies com $25 \%$ de farinha do caroço de açaí e $75 \%$ da mesma farinha e entre as formulações com $50 \%$ de farinha do caroço do açaí e $75 \%$ de farinha ao nível de $5 \%$ de significância.

No entanto, a amostra de biscoito tipo cookie com $25 \%$ e $50 \%$ de farinha do caroço do açaí não se diferenciaram significativamente ao nível de $5 \%$ de significância, sendo que a amostra com $25 \%$ de farinha do caroço do açaí foi a mais preferida pelo teste de Revista Desafios - Suplemento, 2020 
ordenação com $63,07 \%$ dos votos.

Tabela 5. Avaliação sensorial de preferência por ordenação para as amostras de biscoitos tipo cookies enriquecido com diferentes concentrações da farinha do caroço do açaí.

\begin{tabular}{lc}
\hline Diferença da soma de ordens & Módulos da diferença \\
\hline T1 $(20 \%)$ e F2 $(50 \%)$ & $20(\mathrm{~ns})$ \\
T1 $(20 \%)$ e F3 $(70 \%)$ & 64 \\
T2 $(50 \%)$ e F3 $(70 \%)$ & 44 \\
\hline
\end{tabular}

(ns) = não significativo Diferença crítica de $\alpha=0,05=27$

A partir das formulações de biscoitos tipo cookies desenvolvidas e procedendo a metodologia descrita neste trabalho obteve-se a informação nutricional do produto (Tabela 6).

Tabela 6. Informação nutricional das três formulações de biscoitos tipo cookies enriquecido com diferentes concentrações da farinha do caroço do açaí. Valores expressos referente a porção de $10 \mathrm{~g}$ (1 unidade).

\begin{tabular}{lccc}
\hline \multirow{2}{*}{ Componentes } & \multicolumn{3}{c}{ Formulações } \\
\cline { 2 - 4 } & T1 & T2 & T3 \\
\hline Valor energético (kcal) & 34 & 34 & 35 \\
Carboidrato $(\mathrm{g})$ & 2,3 & 2,7 & 2,9 \\
Proteína $(\mathrm{g})$ & 1 & 1 & 1 \\
Lipídeo $(\mathrm{g})$ & 2,3 & 2,2 & 2,1 \\
Fibras bruta $(\mathrm{g})$ & 0,2 & 0,5 & 0,7 \\
\hline
\end{tabular}

As formulações T2 e T3 podem ser classificadas como boas fontes de fibras, de acordo com a diretriz 27/98 (Brasil, 1998), que estabelece um mínimo de $3 \mathrm{~g} / 100 \mathrm{~g}$ de fibras para alimentos sólidos.

Os efeitos atribuídos às fibras como um todo estão relacionados à prevenção de várias patologias do trato gastrointestinal, que são os principais benefícios relacionados principalmente às fibras insolúveis.

\section{CONCLUSÃO}

Os resultados da análise sensorial demonstraram satisfatória aceitação dos cookies com farinha do caroço do açaí. Quanto à intenção de compra, apenas as formulações $\mathrm{T} 1$ e $\mathrm{T} 2$ foram bem aceitas, concluindo-se que seria viável uma possível comercialização.
O enriquecimento de biscoitos tipo cookies com a farinha do caroço do açaí na concentração de $20 \%$ pode ser utilizado com o intuito de melhorar a qualidade nutricional deste gênero alimentício. A adição de $70 \%$ de farinha do caroço do açaí à formulação do cookie provocou perdas na intenção de compra do produto.

Este novo produto pode ser considerado uma fonte de fibras, pois contém de 20 a 70g/100g de fibra para alimentos sólidos.

Todos os autores declararam não haver qualquer potencial conflito de interesses referente a este artigo.

\section{REFERÊNCIAS}

ALVAREZ, D.; BARBUT, S. Efeito da inulina, $\beta$ glucano e suas misturas na estabilidade da emulsão, parâmetros de cor e textura de massas de carne cozida. Meat Science, v. 94, n.3, p. 320-327, 2013.

AOAC. ASSOCIATION OF OFFICIAL ANALYTICAL CHEMISTS. Official Methods as Analysis of the Association of Official Analytical Chemists. 16 ed., Arlington, 1141 p., 1995.

ASSOCIAÇÃO BRASILEIRA DAS INDÚSTRIAS DE BISCOITOS, MASSAS ALIMENTÍCIAS E PÃES E BOLOS INDUSTRIALIZADOS ABIMAPI. Estatísticas. Biscoitos. Ranking global. São Paulo: ABIMAPI, 2018. Disponível em: $<$ https://www.abimapi.com.br/estatisticabiscoitos.php>. Acesso em: 18 de outubro de 2019.

AZEVEDO, A.V.S.; RIBEIRO, M.V.S.; FONSECA, M.T.S.; GUSMÃO, T.A.S.; GUSMÃO, R.P. Avaliação física, físico-química e sensorial de cookies enriquecidos com farinha de açaí. Revista Verde de Agroecologia e Desenvolvimento SustentáveL, Pombal - PB - Brasil), v.10, nº4, p. 49-54, out-dez, 2015.

BAIANO, A.; LAMACCHIA, C.; FARES, C.; TERRACONE, C.; LA NOTTE, E. Comportamento de cozimento e aceitabilidade de massas compostas feitas de sêmola e farinha de soja torrada ou parcialmente desengordurada. LWT-Food Sci Tech, v.44, p.1226-1232, 2011.

BONOMO, L. F.; SILVA, D. N.; BOASQUIVIS, P. F.; PAIVA, F. A.; GUERRA, J. F.; MARTINS, T. A.; TORRES, Á. G. J.; PAULA, I. T.; CANESCHI, W. L.; JACOLOT, P.; GROSSIN, N.; TESSIER, F. J.; Revista Desafios - Suplemento, 2020 
BOULANGER, E.; SILVA, M. E.; PEDROSA, M. L.; OLIVEIRA, R. P. Açaí (Euterpe oleracea Mart.) modulates oxidative stress resistance in Caenorhabditis elegans by direct and indirect mechanisms. PLoS One, v. 9, n. 3, p. e89933, 2014.

BRASIL. Agência Nacional de Vigilância Sanitária. Resolução RDC no 263, de 22 de setembro de 2005. Aprova o "REGULAMENTO TÉCNICO PARA PRODUTOS DE CEREAIS, AMIDOS, FARINHAS E FARELOS", constante do Anexo desta Resolução. publicação: D.O.U. - Diário Oficial da União; Poder Executivo, de 23 de setembro de 2005.

BRASIL. Ministério da Saúde Institui o regulamento técnico referente à informação nutricional complementar. Portaria SVS/MS n⿳0 27, de 13 de janeiro de 1998. Diário Oficial da República Federativa do Brasil. 1998.

CARNEIRO, A. P. G.; SOARES, D. J.; COSTA, J. N.; RODRIGUES, C. S.; MOURA, S. M.; FIGUEIREDO, R. W. Composição e avaliação sensorial de cookies de pó de açaí. Revista Alimentos e Nutrição, Araraquara, v. 23, n. 2, p. 217-221, abr./jun. 2012.

FASOLIN, L.H.; ALMEIDA, G.C.; CASTANHO, P. S.; NETTO-OLIVEIRA, E.R. Biscoitos produzidos com farinha de banana: avaliações química, física e sensorial. Ciência e Tecnologia de Alimentos, v. 27, n. 3, p. 524-529, 2007.

FERREIRA, D.F. Sisvar: a computer statistical analysis system. Revista Ciência e Agrotecnologia. v. 35, p. 1039-1042, 2011.

GOMAA, A.; BOYE, J.I. Impact of thermal processing time and cookie size on the detection of casein, egg, gluten and soy allergens in food. Food Research International, v.52, n. 2, p. 483-489, July, 2013.

HAN, J.; JANZ, J.A.M.; GERLAT, M. Development of gluten-free cracker snacks using pulse flours and fractions. Food Research International, v.43, n.2, p.627-633, March, 2010.

LIMA, H.; CORREAA, N.C.F.; SANTOS, O.; LOURENÇO, L.F.H. Uso de resíduos agroindustriais (fibra de açaí e glicerol) na preparação de biscoitos. Revista de Ciência e Tecnologia de Alimentos. v.52, n.7, p. 4593-4599, 2015.
MACIEL, L. M. B.; PONTES, D. F.; RODRIGUES, M. C. P. Efeito da adição de farinha de linhaça no processamento de biscoito tipo cracker. Revista Alimentos e Nutrição, Araraquara, v.19, n.4, p.385392, 2008.

MADRONA, G. S.; ALMEIDA, A. M. Elaboração de biscoitos tipo cookie à base de okara e aveia. Revista Ciência e Tecnologia de Alimentos, v. 17, p. 61-72, 2008.

MARETI, M.C.; GROSSMANN, M.V.E.; BENASSI, M.T. Características físicas e sensoriais de biscoitos com farinha de soja e farelo de aveia. Ciência e Tecnologia de Alimentos, v. 30, n. 4, p. 878-883, 2010.

MAURO, A.K.; SILVA, V.L.M.; FREITAS, M.C.J. Physical, chemical, and sensorial characterization of cookies made with Kale Stalk Flour (KSF) and Spinach Stalk Flour (SSF) rich in nourishing fiber. Revista de Ciência e Tecnologia de Alimentos, v.30, p.719-728, 2010.

MINISTÉRIO DA SAÚDE. Rotulagem nutricional obrigatória: manual de orientação às indústrias de Alimentos - $2^{\circ}$ Versão - Universidade de Brasília Brasília: Ministério da Saúde, Agência Nacional de Vigilância Sanitária / Universidade de Brasília, 2005. 44p. ISBN 85-88233-17-7.

PEREZ, P. M. P.; GERMANI, R. Elaboração de biscoitos tipo salgado, com alto teor de fibra alimentar, utilizando farinha de berinjela (Solanum melongena, L.). Revista Ciência e Tecnologia de Alimentos, v. 27, n. 1, p. 186-192, 2007.

SILVA, I.G.; ANDRADE, A.P.C.; SILVA, L.M.R.; GOMES, D.S. Elaboration and sensory analysis of cookies made from avocado lump flour. Brazilian Journal of Food Technology, Campinas, v.22, 2019.

SOUZA, M. O.; SANTOS, R. C.; SILVA, M. E.; PEDROSA, M. L. Açaí (Euterpe oleraceae Martius): chemical composition and bioactivity. J. Brazilian Soc. Food Nutr., São Paulo, SP, v. 36, n. 2, p. 161169, ago. 2011.

UNIVERSIDADE ESTADUAL DE CAMPINAS. Tabela Brasileira de Composição de Alimentos. 4. ed. Rev. e Ampl. Campinas: NEPA UNICAMP, 2011. $161 \mathrm{p}$. 